Prins, M.A., Verhaak, P.F.M., Meer, K. van der, Penninx, B.W.J.H., Bensing, J.M. Primary care patients with anxiety and depression: need for care form the patient's perspective. Journal of Affective Disorders: 2009, 119(1-3), 163-171

\begin{tabular}{|l|l|}
\hline $\begin{array}{l}\text { Postprint } \\
\text { Version }\end{array}$ & 1.0 \\
\hline $\begin{array}{l}\text { Journal website } \\
\text { Pubmed link }\end{array}$ & $\underline{\text { http://dx.doi.org/10.1016/j.jad.2009.03.019 }}$ \\
\hline DOI & $\underline{\text { http://www.ncbi.nlm.nih.gov/pubmed/19419771 }}$ \\
\hline
\end{tabular}

This is a NIVEL certified Post Print, more info at http://www.nivel.eu

\title{
Primary care patients with anxiety and depression: Need for care from the patient's perspective
}

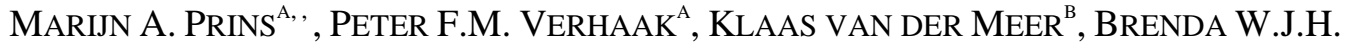 \\ PENNINX ${ }^{\mathrm{D}}$ AND JOZIEN, M. BENSING ${ }^{\mathrm{A}, \mathrm{C}}$ \\ ${ }^{a}$ NIVEL, Netherlands Institute for Health Services Research, P.O. Box 1568, 3500 BN, \\ Utrecht, The Netherlands \\ ${ }^{b}$ Department of General Practice, University Medical Center Groningen, A. Deusinglaan 1, \\ 9713 AV, Groningen, The Netherlands \\ ${ }^{c}$ Department of Clinical and Health Psychology, Utrecht University, The Netherlands \\ ${ }^{\mathrm{d} D e p a r t m e n t}$ of Psychiatry/ EMGO Institute/ Institute for Neurosciences, VU University \\ Medical Center, Amsterdam, The Netherlands
}

\begin{abstract}
Background

Many anxiety and depression patients receive no care, resulting in unnecessary suffering and high costs. Specific beliefs and the absence of a perceived need for care are major reasons for not receiving care. This study aims to determine the specific perceived need for care in primary care patients with anxiety and depression, and examine to what extent these different needs are met.

Methods

Cross-sectional data were derived from The Netherlands Study of Depression and Anxiety (NESDA). In 622 primary care patients with a current (6-month recency) diagnosis of depression and/or anxiety disorder who recognised their mental health problem themselves, the perceived need for mental health care was measured by the Perceived Need for Care Questionnaire (PNCQ). Possible determinants were measured in the same interview by means of a questionnaire.

Results

Most patients with anxiety or depression expressed a need for counselling or information. Medication, practical support, skills training and a referral were less often perceived to be needed. Multiple logistic regression analyses revealed that after controlling for age, clinical status and disability, patients' confidence in professional help and their evaluation of received care positively influenced their perception of a need for medication and counselling.

Conclusions
\end{abstract}


Prins, M.A., Verhaak, P.F.M., Meer, K. van der, Penninx, B.W.J.H., Bensing, J.M. Primary care patients with anxiety and depression: need for care form the patient's perspective. Journal of Affective Disorders: 2009, 119(1-3), 163-171

Although no conclusions can be made about what type of care was specifically not wanted, patients with anxiety or depression mostly want to receive information and counselling. Health professionals should be aware of the fact that there are differences in perceived need for care between subgroups of patients, based on their beliefs and their evaluation of care.

\section{INTRODUCTION}

Anxiety and depression are the most prevalent mental disorders in the world (Wang et al., 2007). However, national health surveys from Australia, the UK, the USA and The Netherlands show that only one third of anxiety and depression patients are treated ([Andrews et al., 2001], [Bebbington et al., 2000], [Bijl and Ravelli, 2000], [Kessler et al., 1994] and [Kessler et al., 2003b]). Attention has been paid to the general practitioner's role in detecting a mental disorder and providing treatment for it ([Hyde et al., 2005], [Klinkman, 2003] and Tiemens, 1999 Tiemens, B.G., 1999. Management of mental health problems in primary care: the doctor, the patient, and the medical model. Academic dissertation, University of Groningen.[Tiemens, 1999]), since the general practitioner (GP) is the main port of call for seeking help for anxiety and depression ([Bijl and Ravelli, 2000], [Andrews et al., 2001] and [Wang et al., 2007]). However, fewer studies have focussed on the patient's perspective. We do know that patients' knowledge and attitudes are important in determining what treatment, if any, will be given (Andrews and Henderson, 2000); and one very important reason for not receiving care is the absence of a perceived need for care ([Verhaak, 1995] and [Verhaak et al., 2009]). Some people think that their GP is not the right person to talk to because he or she is too busy or that the only form of treatment that will be given is medication (Kadam et al., 2001). Others believe that mental health problems should not be discussed at all or can be handled without additional help (Bushnell et al., 2005). As Jorm et al. (1997) have found before, lay people have different beliefs about mental disorders and the best treatment options compared to health professionals. Consequently, patients' perceived need for care and their perception that these needs are being met will be the focus of the current study.

Our systematic review of the health beliefs and perceived needs of anxiety and depression patients (Prins et al., 2008) demonstrates that younger age, female gender, the presence of an affective disorder and comorbidity of anxiety and depressive disorders are positively associated with perceiving a need for treatment for anxiety and depressive disorders ([Meadows et al., 2002], [Mojtabai et al., 2002] and [Aikens et al., 2008]). In addition, the factors marital loss and insurance cover as well as positive attitudes towards mental health care were also found to be associated with a perceived need for professional help, even after controlling for psychopathology (Mojtabai et al., 2002). The youngest and oldest age groups, as well as minority-group patients, seemed to have a lower perceived need for care (Prins et al., 2008). Accordingly, there is some evidence for the influence of socio-demographic variables and clinical status on perceived need. However, patient's beliefs about mental health care and their experiences with care have not been extensively studied to date. Within the context of patient-centred health care (Mead and Bower, 2000) it is important to investigate the patients' perspective on their need for treatment in order to adapt the treatment better to patients' needs.

In this paper, we will determine to what extent patients' self-perceived needs are influenced by their beliefs and their evaluations of received (mental) health care, while taking sociodemographic and clinical factors into account. The questions we address in this study are:

1) What perceived needs for care do people with a current diagnosis of anxiety or depression have and to what extent do they perceive these needs to be met?

2) Does patients' confidence in professional help, self help or help from a friend, or patients' evaluation of received care influence their perceived need for care, while taking age, gender, 
Prins, M.A., Verhaak, P.F.M., Meer, K. van der, Penninx, B.W.J.H., Bensing, J.M. Primary care patients with anxiety and depression: need for care form the patient's perspective. Journal of Affective Disorders: 2009, 119(1-3), 163-171

education level, country of birth and the presence of a depressive or anxiety disorder and general disability into account?

\section{METHODS}

\subsection{Study sample}

Data were derived from the baseline wave of The Netherlands Study of Depression and Anxiety (NESDA), a longitudinal cohort study on the long-term course of depression and anxiety. Details are presented elsewhere (Penninx et al., 2008). Between September 2004 and February 2007, adult patients (aged 18-65 years) were recruited from primary care centres in the vicinity of Amsterdam, Leiden and Groningen. Patients who attended their GP in the last 4 months, irrespective of the reason for consultation, were sent a screening questionnaire containing the Kessler-10 (K-10) to measure the presence of affective or anxiety disorders (Kessler et al., 2003a). The K-10 has proven screening qualities for affective disorders ([Furukawa et al., 2003], [Kessler et al., 2003a] and [Kessler et al., 2003b]). Since the K-10 does not contain questions for specific anxiety disorders, five questions were added concerning the presence (yes/no) of a panic attack, social phobia, agoraphobia, general anxiety or nervousness, and use of psychotropic medication during the last month. Those who returned the screener were more likely to be female (59.3\% versus $50.0 \%, p<0.001$ ) and older (44.4 years versus 39.0 years, $p<0.001$ ) compared to those who did not return it (Penninx et al., 2008). Nearly half of the screeners returned were screenpositive and the individuals concerned were interviewed by phone with the short form of the Composite Interview Diagnostic Instrument (CIDI). Patients who fulfilled the CIDI-short form criteria for a current (6-month recency) depressive or anxiety disorder (except for obsessive compulsive disorder and post-traumatic stress disorder), were asked to participate in NESDA and were invited for a baseline assessment, including a full CIDI interview. Patients with a primary diagnosis of psychotic disorder, obsessive compulsive disorder, posttraumatic stress disorder, bipolar disorder or severe addiction disorder were excluded, since the course trajectory can be strongly affected by these disorders. A second exclusion criterion was lack of fluency in Dutch since language problems would harm the validity and reliability of collected data. Ultimately, 743 patients met the criteria for a current depressive disorder (Major Depressive Disorder (MDD), dysthymia) or an anxiety disorder (generalized anxiety disorder, social phobia, panic disorder, agoraphobia). Fig. 1 presents the complete recruitment flow of NESDA respondents in the primary care setting.

\section{[FIGURE 1]}

\subsection{Perceived need}

The Perceived Need for Care Questionnaire (PNCQ) assessed need from the perspective of the patient, where need is defined as the patient's perception that a type of mental health intervention was needed from a health professional (Meadows et al., 2000a). This needs assessment questionnaire was designed for the Australian National Survey of Mental Health and Well-being and showed acceptable feasibility, reliability and validity for epidemiological and health services research (Meadows et al., 2000b). First, people were asked whether or not they have experienced a mental health problem during the past 6 months. Second, they were asked if they have had contact with different caregivers (for a mental health problem) during the last 6 months. Third, people were questioned about what services they have received for their mental health problem(s). Finally, they were asked if they thought this was enough or, if a service was not received, if they perceived a need for that service. The categories of perceived need, or possible services were: (1) Information about mental illness, its treatment, and available services; (2) Medication; (3) Counselling or psychotherapy to talk about causes of symptoms and learn to cope with emotional problems; (4) Practical support or help to sort out housing or money problems or help with domestic 
Prins, M.A., Verhaak, P.F.M., Meer, K. van der, Penninx, B.W.J.H., Bensing, J.M. Primary care patients with anxiety and depression: need for care form the patient's perspective. Journal of Affective Disorders: 2009, 119(1-3), 163-171

tasks; (5) Skills training to improve one's ability to work, or to use one's time in other ways or help to improve one's ability to look after self or home. For this study, the sixth category (6) "Referral to a specialist" was added as an extra type of intervention. Subsequently, the PNCQ distinguishes between four levels of need (see Table 1) (Meadows et al., 2000b).

\section{[TABLE 1]}

\subsection{Determinants}

Diagnoses of depression and anxiety disorders were assessed with the Composite Interview Diagnostic Instrument (CIDI)-WHO version 2.1 which classifies diagnoses according to the DSM-IV criteria (American Psychiatric Association, 2001). The CIDI is used worldwide, and WHO field research found high interrater reliability (Wittchen et al., 1991), high testretest reliability (Wacker et al., 2006) and high validity for depressive and anxiety disorders ([Wittchen et al., 1989] and [Wittchen, 1994]). Detailed sociodemographic data were collected, including age, sex, education level and years of education, and country of birth named by the respondent.

The World Health Organisation Disability Assessment Schedule II (WHODAS II) (Chwastiak and Von Korff, 2003) assessed disability. This instrument was found to have good psychometric properties; it provides a valid measure of global disability in patients with mental disorders ([Buist-Bouwman et al., 2008] and [Von Korff et al., 2008]).

Patients' values and evaluation of different aspects of care for their mental health problem(s) were measured by the QUOTE instrument (Sixma et al., 1998), revealing five subscales measuring providers' emotional support (Cronbach's alpha $=.78$ ), patient centeredness (Cronbach's alpha $=.82$ ), quality of care (Cronbach's alpha $=.80$ ), information and advice (Cronbach's alpha $=.72$ ), and self-help advice (Cronbach's alpha $=.79$ ). Patients' evaluation of the accessibility of care was measured with one item: "I could get an appointment within 2 days". The items were measured on a 4-point scale: 1 "no"; 2 "actually no"; 3 "actually yes"; 4 "yes", indicating that higher scores correspond to positive evaluations.

Beliefs concerning mental health care were measured by five questions; two measured "confidence in professional help" (Cronbach's alpha $=.80$ ), and two single items measured "confidence in help from friends" (it's best to discuss psychological problems with friends) and "confidence in self-help" (psychological problems are best kept to yourself). Items were scored on a 4-point Likert scale, ranging from 1 "strongly disagree” to 4 "strongly agree".

\subsection{Data analysis}

Data were analysed using SPSS software version 14.0 for windows. First, descriptive statistics were used to outline the characteristics of the patients. Second, service use was examined. Per need category, subgroups of patients were formed who had "no need" or "any need". The subgroup "any need" included patients with a fully met need, partially met need, or unmet need for a certain service. Third, comparisons were made between the two levels of perceived need (no need versus any need) on all measured patient factors (sociodemographics, clinical status, beliefs and evaluations of received care), measured by $\chi^{2}$ or $t$ tests for independent samples. Besides, crosstabs $\left(\chi^{2}\right.$-tests) between any need for medication and any need for counselling or information respectively were made to test whether the observed differences were significant $(P<.05)$.

To determine the association of patient characteristics with perceived need, multiple logistic regression analyses were performed. Odds Ratios (ORs) and Confidence Intervals (CIs) were calculated with perceived need (no need versus any need) as the dependent variable and the patient factors (which differed significantly $(P<.05)$ in the univariate tests) as the independent variables. The Enter method was used, with the sociodemographic and clinical factors being entered in the first block, and the beliefs and evaluation items in the second block. 
Prins, M.A., Verhaak, P.F.M., Meer, K. van der, Penninx, B.W.J.H., Bensing, J.M. Primary care patients with anxiety and depression: need for care form the patient's perspective. Journal of Affective Disorders: 2009, 119(1-3), 163-171

\section{RESULTS}

Of the total of 743 patients with a DSM-IV diagnosis who were selected from the baseline wave of NESDA, 662 confirmed having experienced a mental health problem during the last 6 months. The patients who did not perceive themselves to have a mental problem were consequently omitted from further analyses. Table 2 displays the characteristics of the selected patients. The majority of the patients were female; the mean age was 45 years and most patients had an intermediate or high education level. Nearly $90 \%$ were born in The Netherlands, $63 \%$ had a depressive disorder and $78 \%$ an anxiety disorder. Over $40 \%$ suffered from co-morbidity of both anxiety and depressive disorders.

\section{[TABLE 2]}

\subsection{Need for care}

As shown in Table 3, around one third of these 662 patients received some form of information, medication, counselling or a referral to a specialist (partially or fully met need). Practical support and skills training were received by only $4.1 \%$ and $6.4 \%$ respectively. The majority of patients perceived no need for practical support, skills training or medication. Significantly more patients expressed any need for information (57.9\%) or counselling (60.7\%) compared to any need for medication (41.5\%) (Pearson Chi-square 12.3 and 18.5 respectively; $p<.001$ ). $12.9 \%$ of the 662 patients expressed no need for any of the six services. Few patients perceived partially met needs, of which most were for counselling. We continued our analyses with the division of no need versus any need (whether or not met). In all cases of unmet need, partially met need and met need, there is a need for services.

\section{[TABLE 3]}

\subsection{Determinants}

Table 4 shows the characteristics of patients who perceived no need versus any need for the six different forms of help. For the variables age, anxiety disorder(s) only, comorbidity of anxiety and depressive disorders and disability score, significant differences (in bold) were found on five or more services. Patients who claimed to have no need for information, counselling, skills training or referral were older compared to patients who had any need for these. The contrary was true for medication; patients with no need for this type of help were significantly younger. Patients suffering from anxiety disorder(s) only had significantly more often no need for any of the six services, compared to patients with depressive disorder(s) or comorbidity of both anxiety and depressive disorders, while this latter group expressed more often any need for care. Patients with higher disability scores expressed more often any need for treatment. Patients with more confidence in professional help more often expressed any need for counselling but less often a need for practical support. Patients who evaluated their provider's emotional support more positively perceived a need for medication more often.

\section{[TABLE 4]}

\subsection{Logistic regression analyses}

When all significant variables were put together in a logistic regression model, age seemed to be a significant determinant, indicating that younger patients have an increased probability of experiencing a need for information. Patients from the youngest age group (18-24 years) had the greatest chance of needing information. Patients from the middle age group (2544 years) were significantly more likely to experience a need for skills training and for referral, compared to the oldest age group (45-65 years) (Table 5). Female patients expressed less need for referral than men, and those who were not born in The Netherlands had an increased chance of perceiving a need for information. The presence of an anxiety 
Prins, M.A., Verhaak, P.F.M., Meer, K. van der, Penninx, B.W.J.H., Bensing, J.M. Primary care patients with anxiety and depression: need for care form the patient's perspective. Journal of Affective Disorders: 2009, 119(1-3), 163-171

disorder only influenced the need for counselling and referral negatively, and comorbidity of both depressive and anxiety disorders remained positively associated with a need for medication. General disability scores remained positively associated with a need for practical support and a need for skills training, while associations with other need categories disappeared. When in the second step the beliefs and evaluation variables were entered into the model, patients' confidence in professional help remained positively related to a need for counselling, and confidence in help from friends stayed negatively associated with a need for referral. Finally, patients' evaluation of their provider's emotional support transpired to be positively associated with a need for medication.

\section{[TABLE 5]}

\section{DISCUSSION}

\subsection{Perceived needs}

Dutch general practice patients with one or more anxiety or depressive disorders express more need to talk about their problems and obtain information about it than to receive medication. A similar conclusion was also drawn by Meadows et al. (2000a) from the Australian National Survey. Apparently, Australian and Dutch patients with a common mental disorder mostly need information and counselling, while medication needs are the ones more frequently met. A possible explanation could be found in the fact that patients were recruited from primary care settings, and mostly received care (related to their mental problems) from their GP, while a minority received specialist mental health care (Verhaak et al., 2009). It is possible that patients' expectations about a health care provider have influenced their expressed needs. A general practice consultation takes $10 \mathrm{~min}$ on average, and in about half of all visits medication is prescribed (Cardol et al., 2004). Consequently, one would expect the majority of patients to receive medication instead of counselling, resulting in greater unmet need for counselling and greater met need for medication.

\subsection{Factors influencing perceived needs}

Substantial differences, associated with patient characteristics, are found in rates of perceived need for treatment. Age has a significant influence on perceived need. Patients from the youngest age group are most likely to perceive a need for information, while patients from the middle age group are most likely to need skills training or a referral. The lower need rates among older adults may be explained by the fact that older patients have less knowledge about the possibilities in mental health care or have more "old-fashioned" ideas about treatment and may feel ashamed to seek help. GPs are more accessible and can prescribe medication. Besides, people aged 25-44 years may have a stronger sense of selfefficacy or greater belief in a world where you can influence your own life, resulting in a need to learn to deal with it via skills training or other forms of (cognitive) behaviour therapy. We have no explanation for the fact that men expressed a need for referral more often than women.

Patients' clinical status is of great importance in perceived need for all types of treatment. Patients who suffer from an anxiety disorder only have the lowest chance of perceiving any need for care, while those who suffer from both depression and anxiety disorders have the greatest chance of experiencing a need for care. This finding is in line with the fact that general disability influences nearly all service needs. Apparently, people with more disability are more inclined to express a need for care.

When all significant socio-demographic and clinical characteristics were taken into account, "confidence in professional help" remained positively related to the need for counselling. This is not very surprising, since someone with positive views about psychiatry or psychotherapy will easily see that help from a psychologist or psychiatrist can be useful in dealing with mental health problems. In addition, if patients have experienced more 
Prins, M.A., Verhaak, P.F.M., Meer, K. van der, Penninx, B.W.J.H., Bensing, J.M. Primary care patients with anxiety and depression: need for care form the patient's perspective. Journal of Affective Disorders: 2009, 119(1-3), 163-171

“emotional support from their health care provider”, they experience more need for medication. It is known that subtle interaction between GP and patient is very important in mental health care (Zantinge et al., 2007). GPs' empathy, eye contact and questioning about psychological or social topics correspond with more awareness by GPs of psychological problems, and this cognizance is a prerequisite to finding appropriate care. Finally, patients who have more confidence in help from their friends are less likely to perceive a need for referral, which is in line with what one would expect.

\subsection{Limitations}

This study has some limitations. First, the conclusions are based on cross-sectional data, meaning that no cause-effect relationships can be found. However, the measurements conducted in this study will be repeated three more times within 8 years in the whole NESDA sample. Accordingly, longitudinal data will be available within a few years.

Second, participants were asked whether they needed certain services if they did not receive them. However, we did not measure whether people think the services they received were unnecessary, excessive or unwanted. Consequently, patients' views about overuse of care or what type of help is unwanted remains unclear. This is important information, so questions about perceived overuse or unwanted use of care should be incorporated into possible adaptations of the PNCQ.

Third, perceived need for care, beliefs and evaluations concerning mental health care were measured by self-report questionnaires and a structured interview. Patients could have influenced their answers positively or negatively, whether intentionally or not. Even so, no good alternatives are available to measure these aspects without asking the patients directly.

The last two limitations can be found in the selection of participants. Patients were aged between 18 and 65 years and were recruited from primary care settings in the vicinity of three big cities in The Netherlands. As a consequence, we have no information on older people's perceived need for care, and people from urbanized parts of the country are somewhat overrepresented.

\subsection{Clinical implications}

The perceived needs and associated factors, as found in this study, will have clinical implications. Most patients in this and previous studies (Prins et al., 2008) prefer counselling over other forms of care, including medication. Besides, they want more information about the mental health condition and its treatment. Strategies to increase access to counselling and information in primary care are likely to increase the total number of patients entering into depression care. The past few years have seen various initiatives to strengthen primary care in The Netherlands. Recently, a new position of "nurse practitioner" who deals with mental health problems in primary care, was introduced. These new health care providers should contribute to improving mental health care in primary care settings by clarifying the problem to both GP and patient, giving advice and managing the (referral) process (Have ten, 2007). Because of these mental health nurse practitioners, information needs will be met more often. Collaborative care models used in primary care in the US have proved to be very effective for depression care and they increase the likelihood that patients receive psychotherapy (Unützer et al., 2002). Therefore, more intensive collaboration between various disciplines or the appointment of care managers for common mental disorders is recommended. Otherwise, GPs should follow refresher courses to learn counselling skills and techniques or refer a patient more often to another (primary care) mental health professional. Health care providers should keep in mind that patient characteristics will in fact influence perceived need. Generally, the best way to decide what type of treatment (if any) a patient should receive is by discussing the different options and decide via the shared decision making process which option will be chosen (Elwyn et al., 2003). 
Prins, M.A., Verhaak, P.F.M., Meer, K. van der, Penninx, B.W.J.H., Bensing, J.M. Primary care patients with anxiety and depression: need for care form the patient's perspective. Journal of Affective Disorders: 2009, 119(1-3), 163-171

\section{CONCLUSION}

General practice patients with anxiety or depression mostly need to receive information about their mental health problem and possible treatment options, and they prefer to talk about the problem. Perceived need for care is greater in younger patients, patients with both depressive and anxiety disorders and those with greater disability. Evidence is found that confidence in professional help and positive experiences with a health care provider influence perceived treatment needs significantly, even when socio-demographic and clinical factors are taken into account. Future research should replicate these findings.

\section{ROLE OF FUNDING SOURCE}

The infrastructure for the NESDA study (www.nesda.nl) is funded through the Geestkracht program of the Netherlands Organisation for Health Research and Development (ZonMw, grant number 10-000-1002) and is supported by participating universities and mental health care organizations (VU University Medical Center, GGZ inGeest, Arkin, Leiden University Medical Center, GGZ Rivierduinen, University Medical Center Groningen, Lentis, GGZ Friesland, GGZ Drenthe, IQ healthcare, Netherlands Institute for Health Services Research (NIVEL) and Netherlands Institute of Mental Health and Addiction (Trimbos).

Support for data-analyses for the present study was provided by a grant from the Health Care Efficiency Research Programme, subprogram implementation (grant number 945-14413).

Zon-Mw had no further role in study design, in the collection, analysis and interpretation of data, in the writing of the report, and in the decision to submit the paper for publication.

\section{CONFLICT OF INTEREST}

All authors declare to have no conflict of interests.

\section{REFERENCES}

Aikens et al., 2008 J.E. Aikens, D.E. Nease and M.S. Klinkman, Explaining patients' beliefs about the necessity and harmfulness of antidepressants, Ann. Fam. Med. 6 (2008), pp. 2329.

Andrews and Henderson, 2000 In: G. Andrews and S. Henderson, Editors, Unmet need in psychiatry. Problems, resources, responses, Cambridge University Press, Cambridge (2000).

Andrews et al., 2001 G. Andrews, S. Henderson and W. Hall, Prevalence, comorbidity, disability and service utilisation. Overview of the Australian National Mental Health Survey, Br. J. Psychiatry 178 (2001), pp. 145-153.

American Psychiatric Association, 2001 American Psychiatric Association, Diagnostic and Statistic Manual of Mental Disorders, fourth edition. Washington (2001).

Bebbington et al., 2000 P.E. Bebbington, T.S. Brugha, H. Meltzer, R. Jenkins, C. Ceresa, M. Farrel and G. Lewis, Neurotic disorders and the receipt of psychiatric treatment, Psychol. Med. 30 (2000), pp. 1369-1376.

Bijl and Ravelli, 2000 R.V. Bijl and A. Ravelli, Psychiatric morbidity, service use, and need for care in the general population: results of The Netherlands Mental Health Survey and Incidence Study, Am. J. Public Health 90 (2000), pp. 602-607.

Buist-Bouwman et al., 2008 M.A. Buist-Bouwman, J. Ormel, R. de Graaf, G. Vilagut, J. Alonso, E. van Sonderen, W.A.M. Vollebergh and The ESEMeD/MHEDEA 2000 investigators, Psychometric properties of the World Health Organization Disability Assessment Schedule used in the European Study of the Epidemiology of Mental Disorders, Int. J. Methods Psychiatr. Res. 17 (2008), pp. 185-197.

Bushnell et al., 2005 J. Bushnell, D. McLeod, A. Dowell, C. Salmond, S. Ramage, S. Collings, P. Ellis, M. Kljakovic, L. McBain and for the MaGPle Research Group, Do patients want to disclose psychological problems to GPs?, Fam. Pract. 22 (2005), pp. 631-637.

Cardol et al., 2004 Cardol, M., van Dijk, L., de Jong, J.D., de Bakker, D.H., Westert, G.P., 2004. Tweede Nationale Studie naar ziekten en verrichtingen in de huisartspraktijk. 
Prins, M.A., Verhaak, P.F.M., Meer, K. van der, Penninx, B.W.J.H., Bensing, J.M. Primary care patients with anxiety and depression: need for care form the patient's perspective. Journal of Affective Disorders: 2009, 119(1-3), 163-171

Huisartsenzorg: wat doet de poortwachter? [Second Dutch National Survey of General Practice. General practice care: what does the gatekeeper?] Utrecht/Bilthoven, The Netherlands: NIVEL/RIVM.

Chwastiak and VonKorff, 2003 L.A. Chwastiak and M. Von Korff, Disability in depression and back pain: evaluation of the World Health Organization Disability Assessment Schedule (WHO DAS II) in a primary care setting, J. Clin. Epidemiol. 56 (2003), pp. 507-514.

Elwyn et al., 2003 G. Elwyn, A. Edwards and N. Britten, Doing prescribing": how doctors can be more effective, BMJ 327 (2003), pp. 864-867.

Furukawa et al., 2003 T.A. Furukawa, R.C. Kessler, T. Slade and G. Andrews, The performance of the $\mathrm{K} 6$ and $\mathrm{K} 10$ screening scales for psychological distress in the Australian National Survey of Mental Health and Well-Being, Psychol. Med. 33 (2003), pp. 357-362.

Have ten, 2007 Have ten, J.J.I.M., 2007. Praktijkondersteuning GGZ in de eerste lijn. [Practice support Mental Health Care in primary care]. Landelijke Vereniging Georganiseerde eerste lijn (LVG). [National Association Organised Primary Care]. The Netherlands, Utrecht. Available at: http://www.Ivg.org/doet/publicaties/docs/PraktijkondersteuningGGZmei2007.pdf. Accessed 8 July 2008.

Hyde et al., 2005 J. Hyde, J. Evans, D. Sharp, T. Croudace, G. Harrison, G. Lewis and R. Araya, Deciding who gets treatment for depression and anxiety: a study of consecutive GP attenders, Br. J. Gen. Pract. 55 (2005), pp. 846-853.

Jorm et al., 1997 A.F. Jorm, A.E. Korten, P.A. Jacomb, B. Rodgers, P. Pollitt, H. Christensen and S. Henderson, Helpfulness of interventions for mental disorders: beliefs of health professionals compared with the general public, Br. J. Psychiatry 171 (1997), pp. 233-237.

Kadam et al., 2001 U.T. Kadam, P. Croft, J. McLeod and M. Hutchinson, A qualitative study of patients' views on anxiety and depression, Br. J. Gen. Pract. 51 (2001), pp. 375-380.

Kessler et al., 1994 R.C. Kessler, K.A. McGonagle, S. Zhao, C.B. Nelson, M. Hughes, S. Eshleman, H.-U. Wittchen and K.S. Kendler, Lifetime and 12-month prevalence of DSM-III$\mathrm{R}$ psychiatric disorders in the United States. Results from the National Comorbidity Survey, Arch. Gen. Psychiatry 51 (1994), pp. 8-19.

Kessler et al., 2003a R.C. Kessler, P.R. Barker, L.J. Colpe, J.F. Epstein, J.C. Gfroerer, E. Hiripi, M.J. Howes, S.L. Normand, R.W. Manderscheid, E.E. Walters and A.M. Zaslavsky, Screening for serious mental illness in the general population, Arch. Gen. Psychiatry 60 (2003), pp. 184-189.

Kessler et al., 2003b R.C. Kessler, P. Berglund, O. Demler, R. Jin, D. Koretz, K.R. Merikangas, A.J. Rush, E.E. Walters and P.S. Wang, The epidemiology of major depressive disorder. Results from the National Comorbidity Survey Replication (NCS-R), JAMA 289 (2003), pp. 3095-3105.

Klinkman, 2003 M.S. Klinkman, The role of algorithms in the detection and treatment of depression in primary care, J. Clin. Psychiatry 64 (2) (2003), pp. 19-23.

Mead and Bower, 2000 N. Mead and P. Bower, Patient-centredness: a conceptual framework and review of the empirical literature, Soc. Sci. Med. 51 (2000), pp. 1087-1110. Meadows et al., 2000a G. Meadows, P. Burgess, E. Fossey and C. Harvey, Perceived need for mental health care, findings from the Australian National Survey of Mental Health and Well-being, Psychol. Med. 30 (2000), pp. 645-656.

Meadows et al., 2000b G. Meadows, C. Harvey, E. Fossey and P. Burgess, Assessing perceived need for mental health care in a community survey: development of the Perceived Need for Care Questionnaire (PNCQ), Soc. Psychiatry Psychiatr. Epidemiol. 35 (2000), pp. 427-435.

Meadows et al., 2002 G. Meadows, P. Burgess, I. Bobevski, E. Fossey, C. Harvey and S.T. Liaw, Perceived need for mental health care: influences of diagnosis, demography and disability, Psychol. Med. 32 (2002), pp. 299-309.

Mojtabai et al., 2002 R. Mojtabai, M. Olfson and D. Mechanic, Perceived need and helpseeking in adults with mood, anxiety, or substance use disorders, Arch. Gen. Psychiatry 59 (2002), pp. 77-84.

Penninx et al., 2008 B.W.J.H. Penninx, A.T. Beekman, J.H. Smit, F.G. Zitman, W.A. Nolen, P. Spinhoven, P. Cuijpers, P.J. de Jong, H.W. van Marwijk, W.J. Assendelft, K. van der Meer, P. Verhaak, M. Wensing, R. de Graaf, W.J. Hoogendijk, J. Ormel and R. van Dyck, 
Prins, M.A., Verhaak, P.F.M., Meer, K. van der, Penninx, B.W.J.H., Bensing, J.M. Primary care patients with anxiety and depression: need for care form the patient's perspective. Journal of Affective Disorders: 2009, 119(1-3), 163-171

The Netherlands Study of Depression and Anxiety (NESDA): rationale, objectives and methods, Int. J. Methods Psychiatr. Res. 17 (2008), pp. 121-140.

Prins et al., 2008 M.A. Prins, P.F.M. Verhaak, J.M. Bensing and K. van der Meer, Health beliefs and perceived need for mental health care of anxiety and depression-the patients' perspective explored, Clin. Psychol. Rev. 28 (2008), pp. 1038-1058.

Sixma et al., 1998 H.J. Sixma, J.J. Kerssens, C.V. Campen and L. Peters, Quality of care from the patients' perspective: from theoretical concept to a new measuring instrument, Health Expect. 1 (1998), pp. 82-95.

Tiemens, 1999 Tiemens, B.G., 1999. Management of mental health problems in primary care: the doctor, the patient, and the medical model. Academic dissertation, University of Groningen.

Unutzer et al., 2002 J. Unutzer, W. Katon, C.M. Callahan, J.W. Williams, E. Hunkeler, L. Harpole, M. Hoffing, R.D. Della Penna, P.H. Noel, E.H. Lin, P.A. Arean, M.T. Hegel, L. Tang, T.R. Belin, S. Oishi and C. Langston, Collaborative care management of late-life depression in the primary care setting: a randomized controlled trial, JAMA 288 (2002), pp. 2836-2845.

Verhaak, 1995 P.F.M. Verhaak, Mental disorder in the community and in general practice: Doctors' views and patients' demands. Avebury (1995).

Verhaak et al., 2009 P.F.M. Verhaak, M.A. Prins, P. Spreeuwenberg, S. Draisma, A. van Balkom, J.M. Bensing, M.G.H. Laurant, H.W.J. van Marwijk, K. van der Meer and B.W.J.H. Penninx, Receiving treatment for common mental disorders, Gen. Hosp. Psych. 31 (1) (2009), pp. 46-55.

Von Korff et al., 2008 M. Von Korff, P.K. Crane, J. Alonso, G. Vilagut, M.C. Angermeyer, R. Bruffaerts, G. de Girolamo, O. Gureje, R. de Graaf, Y. Huang, N. Iwata, E.G. Karam, V. Kovess, C. Lara, D. Levinson, J. Posada-Villa, K.M. Scott and J. Ormel, Modified WHODAS-II provides valid measure of global disability but filter items increased skewness, J. Clin. Epidemiol. 61 (2008), pp. 1132-1143.

Wacker et al., 2006 H.R. Wacker, R. Battegay, R. Mullejans and C. Schlosser, Using the CIDI-C in the general population. In: C.N. Stefanis, A.D. Rabavilas and C.R. Soldatos, Editors, Psychiatry: A World Perspective, Elsevier Science Publishers, Amsterdam (2006), pp. 138-143.

Wang et al., 2007 P.S. Wang, S. Aguilar-Gaxiola, J. Alonso, M.C. Angermeyer, G. Borges, E.J. Bromet, R. Bruffaerts, G. de Girolamo, R. de Graaf, O. Gureje, J.M. Haro, E.G. Karam, R.C. Kessler, V. Kovess, M.C. Lane, S. Lee, D. Levinson, Y. Ono, M. Petukhova, J. Posada-Villa, S. Seedat and J.E. Wells, Use of mental health services for anxiety, mood, and substance disorders in 17 countries in the WHO world mental health surveys, Lancet 370 (2007), pp. 841-850.

Wittchen et al., 1989 H.U. Wittchen, J.D. Burke, G. Semler, H. Pfister, M. Von Cranach and M. Zaudig, Recall and dating of psychiatric symptoms. Test-retest reliability of time-related symptom questions in a standardized psychiatric interview, Arch. Gen. Psychiatry 46 (1989), pp. 437-443.

Wittchen et al., 1991 H.U. Wittchen, L.N. Robins, L.B. Cottler, N. Sartorius, J.D. Burke and D. Regier, Cross-cultural feasibility, reliability and sources of variance of the Composite International Diagnostic Interview (CIDI). The Multicentre WHO/ADAMHA Field Trials, $\mathrm{Br}$. J. Psychiatry 159 (1991), pp. 645-653 658.

Wittchen, 1994 H.U. Wittchen, Reliability and validity studies of the WHO-Composite International Diagnostic Interview (CIDI): a critical review, J. Psychiatr. Res. 28 (1994), pp. 57-84.

Zantinge et al., 2007 E.M. Zantinge, P.F. Verhaak, D.H. de Bakker, J.J. Kerssens, K. van der Meer and J.M. Bensing, The workload of general practitioners does not affect their awareness of patients' psychological problems, Patient Educ. Couns. 67 (2007), pp. 93-99. 
Prins, M.A., Verhaak, P.F.M., Meer, K. van der, Penninx, B.W.J.H., Bensing, J.M. Primary care patients with anxiety and depression: need for care form the patient's perspective. Journal of Affective Disorders: 2009, 119(1-3), 163-171

\section{TABLES AND FIGURE}

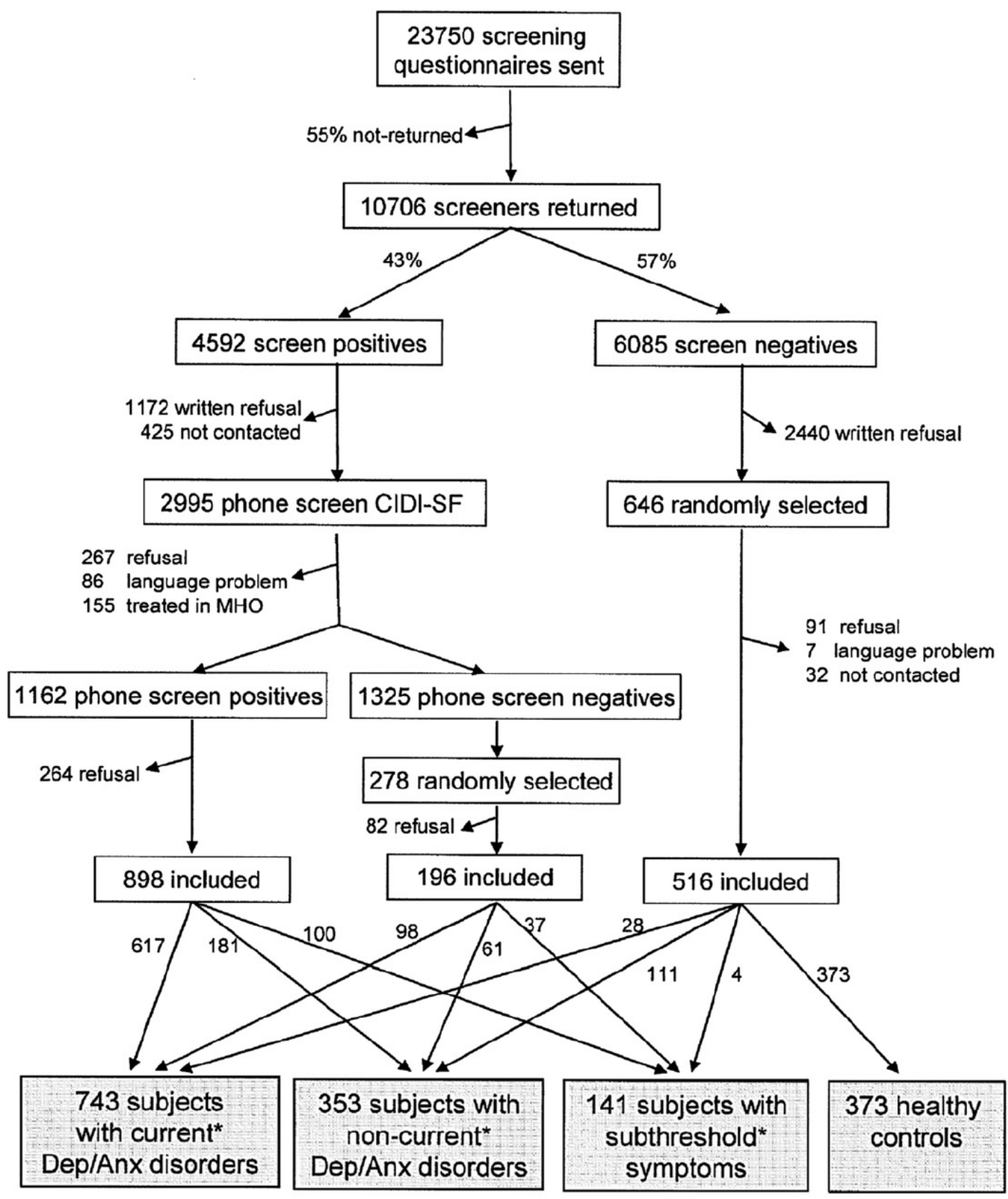

* Current $=$ presence during last 6 months, non-current $=$ presence before last 6 months, subthreshold symptoms defined as screenpositives or having a minor depression according to the CIDI interview

Fig. 1. Recruitment flow of NESDA respondents in the primary care setting. 
Prins, M.A., Verhaak, P.F.M., Meer, K. van der, Penninx, B.W.J.H., Bensing, J.M. Primary care patients with anxiety and depression: need for care form the patient's perspective. Journal of Affective Disorders: 2009, 119(1-3), 163-171

\section{Table 1}

Levels of perceived need and questionnaire phrasing.

\begin{tabular}{|c|c|}
\hline $\begin{array}{l}\text { Level of perceived } \\
\text { need }\end{array}$ & Questionnaire phrasing \\
\hline No need & $\begin{array}{l}\text { Has a mental health problem but did not perceive that they } \\
\text { needed this type of help, and received no service of this type. }\end{array}$ \\
\hline Unmet need & $\begin{array}{l}\text { Perceived that they needed this type of help, but } \\
\text { received no service of this type. }\end{array}$ \\
\hline Partially met need & $\begin{array}{l}\text { Received this type of help, but not as much as they } \\
\text { perceived they needed. }\end{array}$ \\
\hline Met need & $\begin{array}{l}\text { Received this type of help, and received as much as they } \\
\text { perceived they needed. }\end{array}$ \\
\hline
\end{tabular}

\section{Table 2}

Patient characteristics $(N=662)$.

\begin{tabular}{ll}
\hline Age (mean, range) & $44.9(18-65)$ \\
Age categories (\%) & 5.4 \\
18-24 years & 39.4 \\
25-44 years & 55.1 \\
45-65 years & 71.1 \\
Female (\%) & \\
Education level (\%) & 9.5 \\
Basic & 58.5 \\
Intermediate & 32.0 \\
High & $11.8(5-18)$ \\
Years of education (mean, range) & $1.03(1-2)$ \\
Number of nationalities (mean, range) & \\
Country of birth (\%) & 87.8 \\
The Netherlands & 78.2 \\
At least one anxiety disorder (\%) & 27.6 \\
Generalized anxiety disorder & 37.3 \\
Social phobia & 12.1 \\
Agoraphobia without panic & 36.0 \\
Panic disorder (with \& without agoraphobia) & 63.6 \\
At least one depressive disorder (\%) & 16.9 \\
Dysthymia & 26.7 \\
MDD single episode & 33.4 \\
MDD recurrent episode & 36.4 \\
Anxiety disorder(s) only (\%) & 21.8 \\
Depressive disorder(s) only (\%) & 41.8 \\
Comorbidity of both depressive and anxiety disorders (\%) & \\
Number of CIDI diagnosis & $1.90(0.99)$ \\
Mean (SD) & $1-5$ \\
Range &
\end{tabular}


Table 3

Patients' perceived need for mental health services $(N=662)$.

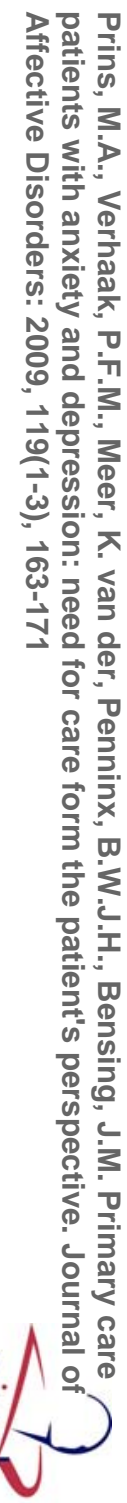

\begin{tabular}{|c|c|c|c|c|c|c|}
\hline & $\begin{array}{l}\text { Information } \\
(662)(\%)\end{array}$ & $\begin{array}{l}\text { Medication }{ }^{1} \\
(656)(\%)\end{array}$ & $\begin{array}{l}\text { Counselling/psychotherapy }{ }^{1} \\
\text { (659) (\%) }\end{array}$ & $\begin{array}{l}\text { Practical support }{ }^{1} \\
(660)(\%)\end{array}$ & $\begin{array}{l}\text { Skills training }{ }^{1} \\
(658)(\%)\end{array}$ & $\begin{array}{l}\text { Referral }^{1} \\
(659)(\%)\end{array}$ \\
\hline No need** & $279(42.1)$ & $384(58.5)$ & $259(39.3)$ & $566(85.8)$ & $510(77.5)$ & $331(50.2)$ \\
\hline Unmet need** & $182(27.5)$ & $57(8.7)$ & $182(27.6)$ & $67(10.2)$ & $106(16.1)$ & $138(20.9)$ \\
\hline Partially met need* & $45(6.8)$ & $22(3.4)$ & $68(10.3)$ & $13(2.0)$ & $15(2.3)$ & $43(6.5)$ \\
\hline Fully met need* & $156(23.6)$ & $193(29.4)$ & $150(22.8)$ & $14(2.1)$ & $27(4.1)$ & $147(22.3)$ \\
\hline
\end{tabular}


Table 4

Patient characteristics: differences between No Need (NN) and Any Need (AN).

\begin{tabular}{|c|c|c|c|c|c|c|c|c|c|c|c|c|}
\hline & \multicolumn{2}{|c|}{ Information } & \multicolumn{2}{|c|}{ Medication } & \multicolumn{2}{|c|}{ Counselling } & \multicolumn{2}{|c|}{ Practical support } & \multicolumn{2}{|c|}{ Skills training } & \multicolumn{2}{|c|}{ Referral } \\
\hline & NN & AN & NN & AN & NN & AN & NN & AN & NN & AN & NN & AN \\
\hline $\bar{N}$ & 279 & 383 & 384 & 272 & 259 & 400 & 566 & 94 & 510 & 148 & 331 & 328 \\
\hline \multicolumn{13}{|l|}{ Socio-demographics } \\
\hline Age (mean) & $46.8^{\ddagger}$ & 43.5 & $43.7 * *$ & 46.6 & $46.7 * *$ & 43.7 & 44.9 & 44.5 & $45.8^{\ddagger}$ & 41.5 & $46.1 * *$ & 43.6 \\
\hline Gender, male (\%) & 26.9 & 30.3 & 27.1 & 31.6 & 26.3 & 30.5 & 29.5 & 24.5 & 27.5 & 33.8 & $25.4^{*}$ & 32.3 \\
\hline \multicolumn{13}{|l|}{ Education level } \\
\hline Low (\%) & 9.0 & 9.9 & 7.6 & 12.5 & 9.3 & 9.8 & $8.5^{*}$ & 16.0 & 10.4 & 6.8 & 8.5 & 10.7 \\
\hline Middle (\%) & 57.0 & 59.5 & 59.6 & 57.4 & 62.9 & 55.5 & 58.0 & 60.6 & 59.0 & 55.4 & 60.4 & 56.1 \\
\hline High (\%) & 34.1 & 30.5 & 32.8 & 30.1 & 27.8 & 34.8 & 33.6 & 23.4 & 30.6 & 37.8 & 31.1 & 33.2 \\
\hline Years (mean) & 11.9 & 11.8 & 12.0 & 11.6 & 11.5 & 12.0 & $12.0^{*}$ & 11.0 & $11.7 *$ & 12.5 & 11.9 & 11.8 \\
\hline Country of birth: The Netherlands (\%) & $91.0^{*}$ & 85.4 & 88.0 & 87.9 & 90.7 & 86.0 & $89.4^{* *}$ & 77.7 & 88.8 & 84.5 & 90.0 & 85.4 \\
\hline \multicolumn{13}{|l|}{ Clinical status } \\
\hline Anxiety disorder(s) only (\%) & $42.3^{* *}$ & 32.1 & $44.3^{\ddagger}$ & 25.4 & $46.3^{\ddagger}$ & 30.0 & $37.8^{*}$ & 27.7 & $39.4^{* *}$ & 26.4 & $44.1^{\ddagger}$ & 28.7 \\
\hline Depressive disorder(s) only (\%) & 19.0 & 23.8 & 23.7 & 19.1 & 19.7 & 23.2 & 22.6 & 17.0 & 21.0 & 25.0 & 22.1 & 21.6 \\
\hline Comorbidity of both depressive and anxiety disorders (\%) & 38.7 & 44.1 & $32.0^{\ddagger}$ & 55.5 & $34.0^{* *}$ & 46.8 & $39.6^{* *}$ & 55.3 & $39.6^{*}$ & 48.6 & $33.8^{\ddagger}$ & 49.7 \\
\hline Disability/WHODAS score (mean) & $31.2^{* *}$ & 34.6 & $31.1^{\ddagger}$ & 36.2 & $30.6^{* *}$ & 34.8 & $31.7^{\ddagger}$ & 42.7 & $32.0^{\ddagger}$ & 36.9 & $30.9^{\ddagger}$ & 35.4 \\
\hline \multicolumn{13}{|l|}{ Beliefs \& evaluations (mean score) } \\
\hline Confidence in professional help & 3.0 & 3.1 & 3.0 & 3.1 & $3.0^{*}$ & 3.1 & $3.1^{*}$ & 2.9 & 3.1 & 3.1 & 3.0 & 3.1 \\
\hline Confidence in help from friends & 2.4 & 2.4 & 2.5 & 2.4 & 2.5 & 2.4 & 2.4 & 2.4 & 2.4 & 2.4 & $2.5^{*}$ & 2.4 \\
\hline Confidence in self help & 1.8 & 1.8 & 1.8 & 1.8 & 1.9 & 1.8 & 1.8 & 1.9 & 1.8 & 1.7 & 1.8 & 1.8 \\
\hline Evaluation of accessibility & 3.5 & 3.5 & 3.4 & 3.6 & 3.5 & 3.5 & 3.5 & 3.3 & 3.5 & 3.6 & 3.5 & 3.4 \\
\hline Evaluation of provider's emotional support & 3.0 & 3.1 & $2.9^{\ddagger}$ & 3.2 & 3.0 & 3.1 & 3.0 & 3.0 & 3.1 & 3.0 & 3.0 & 3.1 \\
\hline Evaluation of patient-centeredness & 3.2 & 3.3 & 3.2 & 3.3 & 3.1 & 3.3 & $3.3^{*}$ & 2.9 & 3.2 & 3.2 & 3.2 & 3.3 \\
\hline Evaluation of quality of care & 2.9 & 2.9 & 2.9 & 3.0 & 3.0 & 3.0 & $3.0^{*}$ & 2.7 & 3.0 & 2.9 & 2.9 & 2.9 \\
\hline Evaluation of information \& advice & 3.1 & 3.2 & 3.1 & 3.2 & 3.2 & 3.2 & 3.2 & 3.0 & 3.2 & 3.0 & 3.1 & 3.2 \\
\hline Evaluation of self-help advice & 2.9 & 3.0 & 3.0 & 3.0 & 3.0 & 3.0 & 3.0 & 2.8 & 3.0 & 2.8 & 3.0 & 3.0 \\
\hline
\end{tabular}


Prins, M.A., Verhaak, P.F.M., Meer, K. van der, Penninx, B.W.J.H., Bensing, J.M. Primary care patients with anxiety and depression: need for care form the patient's perspective. Journal of Affective Disorders: 2009, 119(1-3), 163-171

Table 5

Multiple logistic regression analysis: patient characteristics influencing (any) perceived need for care.

\begin{tabular}{|c|c|c|c|c|}
\hline & & \multicolumn{3}{|c|}{ Need for Information } \\
\hline & & \multicolumn{2}{|l|}{ OR } & $\mathrm{Cl}$ \\
\hline \multicolumn{5}{|l|}{ Age categories (ref: 45-65 years) } \\
\hline $18-24$ years & \multicolumn{2}{|r|}{3.46} & & $1.52-7.86$ \\
\hline $25-44$ years & \multirow{2}{*}{\multicolumn{2}{|c|}{1.53}} & & $1.09-2.13$ \\
\hline Country of birth (ref: The Netherlands) & & & & $1.00-2.93$ \\
\hline Anxiety disorder(s) only & \multicolumn{2}{|r|}{0.73} & & $0.52-1.02$ \\
\hline \multirow[t]{3}{*}{ Disability/WHODAS } & \multicolumn{2}{|r|}{1.01} & & $1.00-1.02$ \\
\hline & \multicolumn{4}{|c|}{ Need for medication } \\
\hline & $\overline{\mathrm{OR}}$ & $\mathrm{Cl}$ & OR & $\mathrm{Cl}$ \\
\hline \multicolumn{5}{|l|}{ Age categories (ref: $45-65$ years) } \\
\hline $18-24$ years & 0.69 & $0.22-2.11$ & 0.71 & $0.23-2.23$ \\
\hline $25-44$ years & 0.85 & $0.55-1.30$ & 0.89 & $0.57-1.37$ \\
\hline Anxiety disorder(s) only & 0.94 & $0.54-1.64$ & 0.98 & $0.56-1.73$ \\
\hline Comorbidity of both depressive and anxiety disorders & 2.24 & $1.29-3.86$ & 2.22 & $1.27-3.87$ \\
\hline Disability/WHODAS & 1.01 & $0.99-1.02$ & 1.01 & $1.00-1.02$ \\
\hline \multirow[t]{3}{*}{ Evaluation of provider's emotional support } & & & 1.50 & $1.19-1.91$ \\
\hline & \multicolumn{4}{|c|}{ Need for counselling } \\
\hline & $\overline{\mathrm{OR}}$ & $\mathrm{Cl}$ & $\mathrm{OR}$ & $\mathrm{Cl}$ \\
\hline \multicolumn{5}{|l|}{ Age categories (ref: $45-65$ years) } \\
\hline $18-24$ years & 2.48 & $0.86-7.11$ & 2.42 & $0.84-6.98$ \\
\hline $25-44$ years & 1.48 & $0.99-2.20$ & 1.43 & $0.96-2.14$ \\
\hline Anxiety disorder(s) only & 0.48 & $0.29-0.80$ & 0.49 & $0.29-0.82$ \\
\hline Comorbidity of both depressive and anxiety disorders & 0.96 & $0.57-1.64$ & 0.99 & $0.58-1.70$ \\
\hline Disability/WHODAS & 1.01 & $1.00-1.02$ & 1.01 & $1.00-1.02$ \\
\hline \multirow[t]{3}{*}{ Confidence in professional help } & & & 1.66 & $1.11-2.47$ \\
\hline & \multicolumn{4}{|c|}{ Need for practical support } \\
\hline & $\overline{\mathrm{OR}}$ & $\mathrm{Cl}$ & OR & $\mathrm{Cl}$ \\
\hline Years of education & 0.98 & $0.88-1.09$ & 1.00 & $0.89-1.12$ \\
\hline Country of birth (ref: The Netherlands) & 1.62 & $0.60-4.37$ & 1.79 & $0.65-4.90$ \\
\hline Anxiety disorder(s) only & 0.91 & $0.34-2.47$ & 0.80 & $0.29-2.23$ \\
\hline Comorbidity of both depressive and anxiety disorders & 0.87 & $0.34-2.22$ & 0.75 & $0.28-1.97$ \\
\hline Disability/WHODAS & 1.06 & $1.03-1.08$ & 1.06 & $1.03-1.08$ \\
\hline Confidence in professional help & & & 0.66 & $0.33-1.33$ \\
\hline Evaluation of patient-centeredness & & & 0.65 & $0.32-1.30$ \\
\hline \multirow[t]{3}{*}{ Evaluation of quality of care } & & & 0.98 & $0.50-1.91$ \\
\hline & & \multicolumn{3}{|c|}{ Need for skills training } \\
\hline & & $\overline{\mathrm{OR}}$ & & $\mathrm{Cl}$ \\
\hline \multicolumn{5}{|l|}{ Age categories (ref: $4-65$ years) } \\
\hline $18-24$ years & & 1.98 & & $0.89-4.39$ \\
\hline $25-44$ years & & 1.76 & & $1.19-2.62$ \\
\hline Years of education & & 1.09 & & $1.03-1.15$ \\
\hline Anxiety disorder(s) only & & 0.60 & & $0.36-1.01$ \\
\hline Comorbidity of both depressive and anxiety disorders & & 0.92 & & $0.56-1.51$ \\
\hline \multirow[t]{3}{*}{ Disability/WHODAS } & & 1.02 & & $1.01-1.03$ \\
\hline & Need & & & \\
\hline & $\overline{\mathrm{OR}}$ & $\mathrm{Cl}$ & OR & $\mathrm{Cl}$ \\
\hline Age categories (ref: $45-65$ years) & & & & \\
\hline $18-24$ years & 2.36 & $0.87-6.42$ & 2.40 & $0.88-6.55$ \\
\hline $25-44$ years & 1.47 & $0.99-2.19$ & 1.51 & $1.01-2.26$ \\
\hline Gender (ref: male) & 0.51 & $0.33-0.79$ & 0.52 & $0.34-0.80$ \\
\hline Anxiety disorder(s) only & 0.54 & $0.32-0.90$ & 0.52 & $0.31-0.88$ \\
\hline Comorbidity of both depressive and anxiety disorders & 0.91 & $0.54-1.53$ & 0.88 & $0.52-1.48$ \\
\hline Disability/WHODAS & 1.01 & $1.00-1.03$ & 1.00 & $1.00-1.02$ \\
\hline Confidence in help from friends & & & 0.71 & $0.51-0.98$ \\
\hline
\end{tabular}

